\title{
Otro universalismo: Sobre la unidad y diversidad de los derechos humanos*
}

\author{
Another Universalism: On the unity and diversity \\ of Human Rights
}

\author{
SEYla BenhaBiB
}

Yale University

Resumen. La expansión de los derechos humanos, así como su defensa e institucionalización, se ha convertido en el lenguaje indiscutible, aunque no la realidad, de la política global. Este texto plantea la cuestión del universalismo en los sentidos cultural, metafísico, moral y legal en referencia al debate contemporáneo sobre los derechos humanos. Defiendo que existe un derecho moral fundamental, el «derecho a tener derechos» (Hannah Arendt) de todo ser humano a ser reconocido por otros, y a su vez reconocer a otros, como una persona con derecho a respeto moral y a derechos legalmente protegidos dentro de una comunidad humana. Los derechos humanos articulan los principios morales que protegen la libertad comunicativa de los individuos. Estos principios morales son distintos de la positivización legal y de la especificación de estos derechos; existe sin embargo una conexión necesaria y no meramente contingente entre los derechos humanos en tanto que principios morales y su forma legal. La unidad y diversidad de los derechos humanos sólo se puede defender desde la base de un compromiso con formas democráticas de gobierno así como con una sociedad civil y una esfera pública libres. "Otro universalismo» sugiere que los procesos de aprendizaje y las conversaciones, así como los enfrentamientos sobre el alcance y la justificación de los derechos humanos, no son discusiones globales.
AbSTRACT. The spread of human rights, as well as their defense and institutionalization, have become the uncontested language, though not the reality, of global politics. This lecture poses the question of universalism in the cultural, metaphysical, moral and legal senses with reference to the contemporary debate on human rights. I argue that there is one fundamental moral right, the «right to have rights» (Hannah Arendt) of every human being to be recognized by others, and to recognize others in turn, as a person entitled to moral respect and to legally protected rights in a human community. Human rights articulate moral principles protecting the communicative freedom of individuals. Such moral principles are distinct from the legal positivization and specification of rights; nevertheless there is a necessary and not merely contingent connection between human rights as moral principles and their legal form. The unity and diversity of human rights can be defended only on the basis of a commitment to democratic forms of government, a free civil society and public sphere. «Another universalism» suggests that learning processes and conversations as well as confrontation on the extent and justification of human rights are not global exchanges.

* Traducción de David Álvarez. Una primera versión de este trabajo apareció en Proceedings of the American Philosophical Association 81 (2), nov. 2007, 7-32. 
Palabras clave: Universalismo, derechos humanos, derecho de gentes, derecho a tener derechos, democracia, Arendt, Husserl, Dworkin, Nussbaum, Rawls y Walzer.
Key words: universalism, human rights, law of peoples, right to have rights, democracy, Arendt, Husserl, Dworkin, Nussbaum, Rawls and Walzer.

Entre 1934 y 1937, mientras Europa se deslizaba hacia una nueva guerra, un Edmund Husserl ya enfermo componía la serie de reflexiones, notas y conferencias que serían publicadas póstumamente como La crisis de las ciencias europeas y la fenomenología trascendental ${ }^{1}$. A la vista del oscuro horizonte que se congregaban sobre el continente europeo, Husserl dio voz a su premonición y angustia respecto a una inminente crisis de civilización:

«Las verdaderas luchas de nuestro tiempo, las únicas significativas, son las luchas entre una humanidad ya desmoronada y otra que aún arraiga sobre suelo firme, pero que lucha por ese arraigo o, lo que es igual, por uno nuevo» (Crisis, p. 15). Para Husserl esas luchas no eran de naturaleza fundamentalmente política entre las ideologías totalitarias del nazismo y el comunismo de estilo soviético contra la democracia liberal. Se trataba ante todo contiendas filosóficas ${ }^{2}$ (Crisis, p. 15).

En estas circunstancias, lo que más atormentaba a Husserl, y podría muy bien retarnos a nosotros hoy en día, era el posible fin de la universalidad y el racionalismo occidental. Si esta forma de indagación, que tiene su origen en la búsqueda griega de la theoria, no tiene pretensión de universalidad, si es únicamente la manifestación de un mundo de vida (Lebenswelt) cultural entre otros, entonces no puede «decidirse, en palabras de Husserl, si la humanidad

1 Edmund Husserl; La crisis de las ciencias europeas y la fenomenología trascendental, (tr. Jacobo Muñoz y Salvador Mas), Barcelona, Crítica, 1991. todas las referencias en el texto remiten a esta edición y aparecen abreviadas como "Crisis». Ver también Die Krisis die europäischen Wissenshaften und die transzendentale Phänomenologie, edición e introducción de Elisabeth Stroker (Hamburg, Felix Meiner Verlag, 1977).

2 Atrapado entre el positivismo de la escuela de Viena y la ontología existencial de su antiguo alumno Martin Heidegger, Husserl contemplaba la misión de la filosofía como una batalla en dos frentes: mostrar que las modernas ciencias matemáticas de la naturaleza, a pesar de sus logros considerables, no podían definir por sí solos qué cuenta como una «razón». Las cuestiones filosóficas atañen «al hombre en tanto que ser libre, que se autodetermina en su conducta de cara al mundo que constituye su entorno humano y extrahumano» y las ciencias no tienen nada que decir «sobre nosotros en tanto que sujetos de esta libertad», así afirmó (Crisis, p. 6). Husserl estaba igualmente preocupado con otro enfoque dominante en las «ciencias históricas humanas»o las Geistwissenschaften. De acuerdo con este historicismo relativista, «todas las configuraciones del mundo espiritual, los vínculos que han cohesionado a los hombres, los ideales y normas, se forman — simplemente - y deshacen como olas fugitivas, que siempre ha sido así y será siempre, que la razón muta una y otra vez en sinsentido y las obras buenas en castigos». (Crisis, pp. 6-7) «ipodemos darnos por satisfechos con ello?» — pregunta. 
europea lleva en sí una idea absoluta (sic) en lugar de ser un mero tipo antropológico empírico como «China» o «India»» (Crisis, p.16). Para Husserl la reflexión sobre la crisis de las ciencias europeas era esencial no únicamente para comprender el malestar espiritual y político de Europa; implicaba el coraje de defender el legado del racionalismo filosófico desde los griegos no sólo como la forma cognitiva de indagación de un mundo de vida históricamente contingente - Occidente - sino como una que posee pretensión de universalidad para toda la humanidad, para otras formas de vida que se estaban entonces, en palabras de Husserl, «europeizándose cada vez más».

En una conferencia ante la Sociedad Cultural de Viena el 7 y 10 de mayo de 1935, mientras redactaba La crisis de las ciencias europeas, Husserl se muestra más tajante si cabe:

«Formulemos la pregunta: ¿cómo se caracteriza la figura espiritual de Europa? O sea, Europa no en un sentido geográfico, no desde el punto de vista de los mapas, como si fuera posible determinar el conjunto de los hombres que coexisten aquí territorialmente como humanidad europea. Los «dominios» ingleses, los Estados Unidos, pertenecen claramente, en un sentido espiritual, a Europa; no así los esquimales o los indios de las tiendas de campaña de las ferias anuales, ni los gitanos que vagabundean continuamente por Europa. Es manifiesto que bajo el rótulo de Europa lo que está en juego es la unidad de una vida espiritual, de un hacer y de un crear: con todos los objetivos, intereses, preocupaciones y esfuerzos, con las configuraciones teleológicas, con las instituciones y organizaciones» ${ }^{3}$.

Estos intentos, por parte de un Husserl ya mayor, que moriría el 27 de abril de 1938, de salvar un sentido de lo que Occidente tiene en común, diferenciando su legado filosófico y espiritual no sólo de los mundos de las grandes civilizaciones de China e India, sino también de los mundos menores de los esquimales, gitanos e indios (entendiendo por ello los pueblos indígenas de América del Norte y del Sur) son profundamente conmovedores. El de Husserl es un eurocentrismo que, sin sonrojo alguno, encuentra necesario el jerarquizar distintos mundos de vida y totalidades culturales de acuerdo con si son capaces o no de alcanzar «la entelequia de la humanidad» (Husserl), esto es, la razón filosófica universal. Se trata quizás de la más cruel de las ironías que los Nazis, que entrarían en Polonia año y medio después de la muerte de Husserl, pensasen que los judíos de Europa, a los que Husserl pertenecía, lejos de ser los descendientes espirituales de los griegos, guardaban mayor afinidad con los gitanos, otro pueblo de tez oscura, sin tierra y que vaga entre las naciones del mundo. Los campos de concentración europeos devastaron a los sinti y a los roma, junto con los judíos. Husserl tuvo la suerte de no haber experimentado la peor parte y de haber muerto con su fe en el racionalismo europeo intacta.

${ }^{3}$ Husserl, «Conferencias de Viena», Texto Complementario-Tratado I: «La crisis de la humanidad europea y la filosofía», en La crisis de las ciencias europeas, p. 328. 
¿Por qué recordar este episodio? ¿Por qué desempolvar una obra compuesta en un período tan convulso de la historia? Ciertamente, no tengo intención de defender el proyecto de Husserl de una fenomenología trascendental o su búsqueda de una «idea absoluta» acarreada por la humanidad occidental. Sin embargo, sus últimas reflexiones articulan una cuestión que todavía nos acompaña: ¿qué es el universalismo? ¿En que sentido, si lo tiene, es universal el legado del racionalismo occidental? La respuesta de Husserl a estas cuestiones es esencialista: procede identificando el logos como la entelequia -en sus palabras - de la humanidad y afirmando que otras formas de vida culturales, que ciertamente merecen respeto por sus logros ${ }^{4}$, son sin embargo inferiores a la vida occidental de theoria o el espíritu de la contemplación.

${ }^{4}$ Introduzco esta matización porque Husserl también afirma que en India, al igual que en China, se desarrollaron «filosofías similares», que aspiraban a un conocimiento universal del mundo (Husserl, «Conferencias de Viena», p. 335). Estas búsquedas originaron comunidades vocacionales que a su vez transmitieron sus conocimientos de generación en generación. Lo que distingue a la búsqueda griega de theoria de estas otras empresas es su desvinculación de intereses cosmológicos y religioso-comunales, precipitado por la emergencia de una comunidad de hombres, «que teoría y nada más que teoría». (ibid.). Husserl repite aquí unas asunciones sociológicas bien establecidas en su tiempo como que en otras culturas superiores, y en contraste con la experiencia griega, la búsqueda del «conocimiento universal del mundo» nunca se liberó de los intereses y vocaciones de una élite cultural (los brahmanes en India), una casta sacerdotal (los monjes budistas en a lo largo de toda Asia), o una burocracia estatal (los mandarines chinos). Ver Reinhard Bendix, Max Weber. An Intellectual Portrait, con una nueva Introducción de Guenther Roth (University of California Press: Berkeley, 1977), pp. 90 ss. Cf. La pregunta de Max Weber: «¿qué cadena de circunstancias ha conducido al hecho de que en Occidente y sólo en Occidente, han aparecido fenómenos culturales que sin embargo $-\mathrm{O}$ al menos es lo que nos gusta pensar - se hayan en una línea de desarrollo que poseee significado (Bedeutung) y validez (Gültigkeit) universal? [which chain of circumstances has led to the fact that in the West, and in the West alone, cultural phenomena have appeared, which nonetheless-or at least we like to think-lie in a line of development having universal significance $(\mathrm{Be}$ deutung) and validity (Gültigkeit)?»] (Max Weber, Die Protestantische Ethik und der Geist des Kapitalismus. In Gesammelte Aufsätze zur Religionssoziologie, Mohr Verlag, Tübingen, 1920 [1. English translation: The Protestant Ethic and the Spirit of Capitalism, transl. Talcott Parsons (Scribner's: New York, 1958)]. Por razones que detallo en otros lugares, he empleado mi propia traducción de este párrafo en lugar de la habitual de Talcott Parsons. Ver Seyla Benhabib, Critique, Norm and Utopia. A Study of the Foundations of Critical Theory (New York: Columbia University Press, 1986), p. 395, n. 64.

En una serie de artículos influyentes, Amartya Sen ha defendido que algunos de los aspectos más valorados del racionalismo occidental, como la discusión pública, la tolerancia y la consulta de los gobernados, han sido también desarrollados y valorados por otras tradiciones. Ver Amartya Sen, «Elements of a Theory of Human Rights», Philosophy and Public Affairs 32 (2004): 315-56; here p. 352; A. Sen, «Human Rights and Asian Values», The New Republic (July 14 and July 21, 1997): 33-40; A. Sen, «The Reach of Reason: East and West», The New York Review of Books (July 20, 2000): 33-38; A. Sen, «Democracy and its Global Roots», The New Republic (October 2003): 28-35. Resulta evidente que Husserl y Weber se basaban en una teoría comparativa de culturas y civilizaciones que necesita una seria actualización para nuestros tiempos. 
Estas cuestiones se han vuelto más apremiantes en nuestros días. Mientras que a Husserl lo que le preocupaba era el ascenso inminente del fascismo y la retirada de Europa del racionalismo liberal, nosotros hoy nos enfrentamos a la galopante expansión a todos los rincones del mundo, de «nuestro» modo de vida occidental. Éste con frecuencia se escuda en la excusa de la razón de occidente y la Ilustración para colocar a otras culturas bajo la influencia de un capitalismo global inigualitario cuyos efectos no son, de modo evidente, ni racionales ni humanos. El legado del racionalismo occidental ha sido usado y abusado, al servicio de instituciones y prácticas que no soportan el escrutinio de la misma razón que declaran expandir. Al tiempo que el planeta se convierte materialmente en un único mundo, se hace cada vez más urgente el comprender cómo se pueden reconciliar las pretensiones de universalidad con la diversidad de formas de vida.

El vocabulario público en el que se articulan estas cuestiones con mayor exigencia es el lenguaje de los derechos humanos ${ }^{5}$. La expansión de los derechos humanos, así como su defensa e institucionalización, se ha convertido en el lenguaje incontestable, aunque no la realidad, de la política global. Es en estos mismos términos de los derechos humanos en los que me gustaría plantear aquí de nuevo la cuestión de la universalidad. Defenderé que existe un derecho moral fundamental, el «derecho a tener derechos» ${ }^{6}$ de todo ser humano, esto es, de ser reconocido por otros y de reconocer a otros a su vez como persona merecedora de respeto moral y de derechos legalmente garantizados en el seno de una comunidad humana. Defenderé que los derechos humanos articulan principios que protegen la libertad comunicativa de los individuos. Aunque es-

5 Ver Michael Ignatieff, Los derechos humanos como política e idolatría, editado por Amy Gutmann (Barcelona, Paidós, 2003). Empleo el concepto de «un vocabulario público» para diferenciarlo del concepto rawlsiano de «razón pública». La razón pública es fundamentalmente para Rawls del despliegue de la razón como una tarea de justificación en una sociedad liberal pluralista en la que diversas visiones del mundo compiten por la lealtad de los ciudadanos. Ver John Rawls, El Liberalismo Político (Barcelona, Paidós, 1996). La exploración de a totalidad de las diferencias epistemológicas y metodológicas que subyacen entre el concepto rawlsiano de razón pública y el modelo teorético-discursivo que defenderé posteriormente, trasciende los límites de este ensayo. En relación a mi primera crítica de Rawls, ver Seyla Benhabib, «Toward a Deliberative Model of Democratic Legitimacy», in Democracy and Difference, edited by S. Benhabib (Princeton, NJ: Princeton University Press, 1996), 67-95.

${ }^{6}$ La expresión «el derecho a tener derechos» fue acuñada por Hannah Arendt en Los Orígenes del Totalitarismo, The Origins of Totalitarianism [1951] (New York: Harcourt Brace Jovanovich, 1979); originally published in Britain as The Burden of Our Times (London: Secker and Warburg, 1951), en la p. 296. Igualmente Hegel comienza su Filosofía del Derecho con el derecho a la «personalidad», que consiste en el derecho del individuo a la titularidad sobre derechos. Al igual que Arendt, Hegel considera que este estatus emerge del desarrollo de luchas políticas, sociales y culturales en la comunidad mundial, pero también lo considera como la única posición compatible con el concepto moderno de libertad. See G.W.F. Hegel, Grundlinien der Philosophie des Rechts, in Werke in 20 Bd., vol. 7, edited by Eva Moldenhauer and K. Markus Michel (Frankfurt: Suhrkamp, 1970); Hegel's Philosophy of Right, translated by T.M. Knox (Oxford: Oxford University Press, 1973). See section on «Abstraktes Recht». 
tos principios morales son distintos de la especificación moral de los derechos, existe sin embargo una conexión necesaria, y no meramente contingente, entre los derechos humanos como principios morales y su forma legal.

Existe un amplio desacuerdo en el pensamiento contemporáneo sobre la justificación filosófica así como sobre el contenido de los derechos humanos. De hecho se ha destacado que «en los años recientes, mientras que el compromisos político con los derechos humanos ha crecido, el filosófico ha menguado» ${ }^{7}$. Algunos defienden que los derechos humanos constituyen «el núcleo de una moralidad universalista tenue» (Michael Walzer), mientras que otros argumentan que éstos conforman «condiciones razonables para un consenso político mundial» (Martha Nussbaum). Otros estrechan el concepto de derechos humanos a «un estándar mínimo de instituciones políticas bien-ordenadas para todos los pueblos» ${ }^{8}$ (John Rawls) y advierten que es necesario diferenciar entre la lista de derechos humanos incluida en la Ley de los Pueblos, defendible desde el punto de vista de una razón pública mundial, y la Declaración Universal de los Derechos Humanos de 1948.

Estas diferentes justificaciones de los derechos humanos conducen inevitablemente a una cierta variación en su contenido y a la elección arbitraria de entre varias listas de derechos. Michael Walzer, sugiere que una comparación de entre los códigos morales de varias sociedades puede producir un conjunto de estándares, «al que pueden ser sometidos todas las sociedades - mandatos negativos, probablemente, normas contra el asesinato el engaño, la tortura, la opresión y la tiranía» ${ }^{9}$. Pero este modo de proceder generaría una lista relativamente corta. «Entre otros - advierte Charles Beitz - serían con certeza excluidos los derechos que requieren formas políticas democráticas, tolerancia religiosa, igualdad legal para la mujer y la libre elección de pareja» ${ }^{10}$. Desde el punto de vista de muchos de los sistemas morales del mundo, como el judaísmo antiguo, el cristianismo medieval, el confucionismo, el budismo e hinduismo, «los mandatos negativos contra la opresión y la tiranía» de Walzer serían compatibles con enormes grados de desigualdad entre los géneros, clases, castas y grupos religiosos.

Otra sugerencia es la de que una concepción no-parroquial de los derechos humanos, aunque no fuese adoptada necesariamente por todas las moralidades convencionales, puede, de hecho, ser aceptada por las principales concepciones de justicia política y económica del mundo: entendidos de este modo, los derechos humanos constituirían el núcleo de un «solapado consenso» (overlapping

7 Susan Mendus. «Human Rights in Political Theory». Political Studies (1995), xliii, p. 10 .

8 John Rawls. «The Law of Peoples» [1993]. En: Collected Papers, editado por Samuel Freeman (Cambridge, MA: Harvard University Press, 1999), 529-64; p. 552. Existen interesantes diferencias en cuanto a la formulación entre este artículo más antiguo y su libro posterior, The Law of Peoples, que no comento en este ensayo. Ver J. Rawls, The Law of Peoples with «The Idea of Public Reason Revisited» (Cambridge, MA: Harvard University Press, 1999).

9 Michael Walzer. Thick and Thin: Moral Argument at Home and Abroad (Notre Dame, IN: University of Notre Dame Press, 1994). 
consensus) político en vez de moral. La defensa de Martha Nussbaum de los derechos humanos sigue esta estrategia ${ }^{11}$. Concuerdo con que podemos leer los documentos de derecho público de nuestro mundo, como la Declaración Universal de los Derechos Humanos (DUDH), el Pacto Internacional de Derechos Civiles y Políticos, el Pacto Internacional de Derechos Económicos, Sociales y Culturales y la Convención de Ginebra de 1951 con su Protocolo de 1967, como una materialización de ese «solapado consenso político» ${ }^{12}$. Sin embargo, el método de Nussbaum de deducción filosófica, que vincula de un modo demasiado íntimo el concepto de derechos a una antropología filosófica de las capacidades humanas, resulta problemático. No distingue entre derechos en tanto que principios morales y prerrogativas legales por una parte, $\mathrm{y}$ «el principio de los derechos» y la «agenda de los derechos» por la otra. Cuando un Estado de derecho está debidamente constituido, entonces reconoce el principio de los derechos; pero esto deja abierta la cuestión sobre el grado de variación en la enumeración, contenido e interpretación de los derechos que se permite, en el sentido de ser normativamente defendible, entre diferentes «agendas de derechos». Nussbaum concibe una correspondencia uno-a-uno entre la lista de derechos humanos derivada filosóficamente, basada en una teoría moral de las capacidades, y las positivizaciones de legislativos específicos. Así ignora el modo en que pueden emerger variaciones legítimas en las interpretaciones, contextualización y aplicación de los derechos humanos ${ }^{13}$.

10 Charles Beitz. «Human Rights as a Common Concern». American Political Science Review 95 (June 2001): 272.

11 Martha C. Nussbaum. «Capabilities and Human Rights». Fordham Law Review 66 (1997-98): 273-300.

12 La Comisión de Naciones Unidas para los Derechos Humanos, creada en 1946, redactó en su borrador «los más importantes estándares internacionales de derechos humanos, incluyendo los dos convenios internacionales sobre derechos humanos, que, en conjunto, con la Declaración Universal de los Derechos Humanos (1948) adoptada anteriormente, forman lo que se conoce como la Carta Internacional de Derechos Humanos». Yvonne Terlingen. «The Human Rights Council: A New Era in UN Human Rights Work?» Ethics and International Affairs 21 (Summer 2007): 167-79; p. 168. Para la documentación de la Declaración y de los Convenios, ver: Henry J. Steiner and Philip Alston, International Human Rights in Context: Law, Politics, Morals, 2 nd ed (Oxford: Oxford University Press, 2000). Louis Henkin escribe: «En 1999, de 140 a 145 (de cerca de 190 miembros de Naciones Unidas) se han adherido a ambos Convenios, aunque en algunos casos con reservas significativas. En contra de las expectativas y de las anteriores tendencias, hay casi tantos que son partes del Convenio sobre Derechos Civiles y Políticos como del Convenio sobre Derechos Económicos y Sociales». En Realizing Human Rights. Moving from Inspiration to Impact, editado por Samantha Power y Graham Allison (St. Martin's Press: New York, 2000), 3-39; p. 15.

13 Amartya Sen critica el intento de Nussbaum de identificar una lista «omnicomprensiva» de capacidades con el argumento de que esta «lista canónica», así como el peso que se le debe atribuir a los distintos elementos de la lista, no pueden ser escogidos sin una mayor especificación del contexto. De un modo más importante, Sen percibe en este tipo de procedimiento «una disminución sustancial del dominio de la razón pública» (Sen, «Elements of a Theory of Human Rights», p. 333, n. 31). Como argumentaré más adelante, la propia perspectiva de Sen puede ser igualmente criticada por implicar la «disminución del dominio de la razón pública». Ver nota 37. 
Ciertamente, la defensa más provocadora de la limitación de los derechos humanos a «un estándar mínimo de instituciones políticas bien-ordenadas para todos los pueblos» ha sido la de John Rawls. Rawls enumera el derecho a la vida (a los medios de subsistencia y seguridad); a la libertad (a vivir libre de esclavitud, servidumbre y ocupación forzosa y a una suficiente libertad de conciencia que asegure la libertad de conciencia y pensamiento); a la propiedad personal y a la «igualdad formal tal como se expresa en las normas de la justicia natural (esto es, que los casos iguales se tratan de modo similar)» ${ }^{14}$ como los derechos humanos básicos. Los derechos de libertad de conciencia y asociación se recortan en The Law of Peoples (1999) de modo que acomoden a las «decentes, sociedades jerárquicas». Estas sociedades garantizan cierta libertad de conciencia a otros credos mas no igual libertad de conciencia a las religiones minoritarias que no son la oficial del Estado. El artículo 18 de la DUDH, por el contrario, que garantiza «el derecho a la libertad de pensamiento, conciencia y religión», incluyendo el derecho individual a cambiar de religión, «a manifestar la propia religión o credo en la enseñanza, práctica, culto y observancia», es mucho más igualitario y menos condescendiente frente a las religiones estatales existentes que el derecho de Rawls a la «libertad de conciencia no-igualitaria».

De modo más significativo, Rawls soslaya sin comentario el crucial artículo 21 de la Declaración Universal, que garantiza a todos «el derecho a participar en el gobierno de su país, de modo directo a través de representantes libremente elegidos», y que estipula que la voluntad del pueblo debe ser el fundamento de la autoridad del gobierno» ${ }^{15}$. No hay un derecho humano básico al autogobierno en el proyecto de Rawls ${ }^{16}$.

14 Rawls, The Law of Peoples (1999), 65. La lista anterior en el artículo homónimo de 1993 presentaba una formulación ligeramente diferente: aquí se incluían como derechos humanos «los elementos del imperio de la ley, así como el derecho a cierta libertad de conciencia y libertad de asociación, y el derecho a la emigración». (Rawls 1993, p. 554).

15 Ver «The Law of Peoples» (1993), pp. 553-54; The Law of Peoples (1999), pp. 79-80. La principal motivación para limitar de este modo la lista de los derechos humanos que fuese o pudiese ser aprobada por todas las visiones del mundo comprehensivas conocidas y reconocidas en la comunidad global, de tipo moral, religioso, científico, etc. Si o fundamental del liberalismo político es formular una concepción política que los ciudadanos pudiesen aprobar a pesar de la amplia divergencia en sus visiones comprehensivas dentro de una comunidad nacional, lo fundamental de la razón pública en una escala global es formular de un modo similar «una concepción minimalista de los derechos humanos», que pudiese ser apoyada por pueblos con tradiciones religiosas y morales divergentes. Joshua Cohen o explica claramente: «El minimalismo justificativo es animado por un reconocimiento del pluralismo y una aceptación de la tolerancia. Aspira a presentar una concepción de los derechos humanos sin conectar esta concepción a un punto de vista particular, ético o religioso». Joshua Cohen. «Minimalism about Human Rights: The Most We Can Hope For?» The Journal of Political Philosophy 12 (2004): 190-213, p. 192. La estrategia de justificación propuesta por la perspectiva teorético-discursiva, respeta el pluralismo de visiones del mundo sin imagina conceptualmente, por así decir, lo que podrían hipotéticamente acordar un budista y un católico, sino encuadrando y animando que tenga lugar un diálogo real entre un budista y un católico de modo que pueda producir un acuerdo razonable. El énfasis en la ética del discurso se centra en las constriccio- 
Dado que la Declaración Universal de los Derechos Humanos es el documento más cercano en nuestro mundo al derecho internacional público, ¿cómo podemos explicar este intento por parte de los filósofos de restringir el contenido de los derechos humanos a una fracción de lo que está acordado internacionalmente - al menos sobre el papel? No estoy descartando la posibilidad que estos documentos puedan ser filosóficamente confusos, producidos a consecuencia de concesiones políticas - como lo fue la DUDH, que fue objeto de una continua negociación entre las delegaciones de los EE.UU y de la URSS ${ }^{17}$. Sin embargo, estos documentos establecen ciertas normas públicas y estándares que son formalmente reconocidos por la inmensa mayoría de los estados del mundo. Tal como James Griffith ha argumentado, es al menos necesario considerar seriamente las «discrepancias entre la mejor justificación filosófica de los derechos humanos y la legislación internacional sobre derechos humanos» ${ }^{18}$.

nes necesarias para el procedimiento dialógico, que es a su vez lo suficientemente «tenue» como para que no pueda ser identificado con ninguna visión del mundo particular, y por el contrario, lo suficientemente «denso» para guiar la conversación hacia un acuerdo racionalmente justificable. Ésta es al menos mi aspiración cuando defiendo la ética del discurso.

Existe un problema metodológico al identificar a los constituyentes interpelados por la razón pública global con «visiones del mundo» en lugar de con individuos, o incluso con pueblo con historias complejas en las que varias imágenes del mundo se entrecruzan, chocan y buscan o no una síntesis, en función de cada caso. La posición rawlsiana procede a partir de un «holismo metodológico» al razonar sobre estos asuntos y el ensayo de Josh Cohen, «Minimalism about Human Rights», tampoco es inmune a esta crítica. Para una crítica del holismo metodológico y de la deficiente sociología de Rawls en The Law of Peoples, ver Seyla Benhabib, «The Law of Peoples, Distributive Justice, and Migrations», Fordham Law Review LXXII, No. 5 (April 2004): 1761-87.

16 Para un lúcido análisis de la posición ralwsiana, cf. Joshua Cohen, «Is There a Human Right to Democracy?» The Egalitarian Conscience. Essays in Honor of G.A. Cohen, edited by Christine Sypnowich (Oxford: Oxford University Press, 2006), 226-48. En contraste con Cohen defenderé que el derecho humano a la democracia es fundamental para articular lo que el mismo Cohen denomina como una formulación de os derechos humanos como «titularidades que sirven ara asegurar las bases de la pertenencia a una comunidad». Hay un derecho humano a la democracia, precisamente porque sin él la formulación de una «pertenencia justa» proporcionada por Cohen resulta incoherente. Ibid. p. 226. De acuerdo con Cohen, «el elemento central de la noción normativa de pertenencia es que el bien de una persona debe ser tomado en cuenta por las instituciones básicas de la sociedad política: ser tratado como un miembro consiste en que el propio bien sea tomado con la debida consideración, tanto en el proceso de llegar a decisiones colectivas autorizadas como en el contenido de estas decisiones». Ibid., pp. 237-38. No alcanzo a ver cómo se pueden realizar estas condiciones si no es en democracias que funcionen correctamente. Una crítica más detallada de la posición de Cohen aparecerá próximamente en Benhabib, «The Human Right to Democracy and the Vicissitudes of Rawlsian Public Reason», The Kansas University, Lindley Lecture (2008).

17 Cf. Johannes Morsink, The Universal Declaration of Human Rights. Origins, Drafting and Intent (Philadelphia: University of Pennsylvania Press, 1999).

18 James Griffin. «Discrepancies between the Best Philosophical Account of Human Rights and the International Law of Human Rights», The Presidential Address, Proceedings of the Aristotelian Society 101 (2001): 1-28. Los resultados de este examen pueden ser que «algu- 
Deseo argumentar que es necesario mover la estrategia justificatoria y la derivación del contenido de los derechos humanos, lejos de las preocupaciones minimalistas ${ }^{19}$, hacia una comprensión más robusta de los derechos humanos en términos del «derecho a tener derechos». Permítanme reconocer desde el principio que debo la frase «derecho a tener derechos» a Hannah Arendt. Aunque en su obra, sin embargo, este derecho es contemplado principalmente como un derecho político y se identifica estrechamente con el «derecho de pertenencia a una comunidad política», propondré una concepción del «derecho a tener derechos», entendida como la exigencia de cada persona humana a ser reconocida y protegida como una personalidad jurídica por la comunidad mundial. Esta reconceptualización del derecho a tener derechos en términos no estatalistas resulta crucial en el período desde la Declaración de Derechos Humanos de 1948 — un período en el que nos hemos desplazado de unas normas de justicia «internacionales» a unas «cosmopolitas». El discurso contemporáneo sobre los derechos ha fracasado tristemente en tomar nota de estas transformaciones y desarrollar una justificación y un contenido para los derechos humanos en consonancia con estas transformaciones jurídicas.

A continuación, comienzo examinando con más detalle el término «universalismo»; luego desarrollo una articulación discursivo-teorética de los derechos humanos. Ésta, a su vez, conduce a la cuestión sobre si existen ciertas asunciones mínimas sobre la naturaleza humana y la racionalidad que deben subyacer en cualquier formulación normativa de los derechos humanos. El universalismo no puede ser traducido simplemente, sin resto alguno, en una cuestión únicamente jurídico-política. Ciertos compromisos normativos resultan cruciales. Sostengo que los universalismos justificatorio y moral están profundamente entrelazados.

nos de los elementos de la lista son tan erróneos que deben ser, en la medida de lo posible, legalmente ninguneados» (Ibid., p. 26). Estoy de acuerdo, pero Griffin procede de una formulación relativamente convencional de los derechos humanos en tanto que «centrados en la noción de agencia... Valoramos nuestro estatus de agentes de un modo especialmente elevado, con frecuencia por encima incluso de nuestra propia felicidad. Los derechos humanos pueden ser concebidos como protecciones para nuestra agencia - lo que uno podría llamar nuestra personalidad» (Ibid., p. 4) - Esta defensa de los derechos humanos está sujeta a las mismas críticas que el resto de las visiones centradas en el agente: que ciertas condiciones resulten necesarias para el ejercicio de $m i$ agencia no impone una obligación sobre $t i$ para que respetes esta condición, a no ser que tú y yo reconozcamos la mutua igualdad y reciprocidad en tanto que seres morales. Éste es el primer paso justificatorio en el argumento. Ver nota 28.

19 Para una defensa de Rawls, ver Joshua Cohen, «Minimalism about Human Rights: The Most We Can Hope For?» The Journal of Political Philosophy, pp. 190-213. Para una interesante crítica de Rawls respecto al derecho a la democracia, ver Alessandro Ferrara, «Two Notions of Humanity and the Judgment Argument for Human Rights», Political Theory 31, No. X (2003): 1-30; pp. 3 y ss. 
III.

Permítanme comenzar distinguiendo entre universalismo esencialista, justificatorio, moral y jurídico ${ }^{20}$.

1. Universalismo puede significar la creencia de que existe una naturaleza humana fundamental o una esencia humana que define quiénes somos en tanto que humanos. Algunos afirman, tal como lo hicieron los filósofos del siglo XVIII, que la naturaleza humana consiste en pasiones y disposiciones estables y predecibles, instintos y emociones, todo ello susceptible de ser descubierto racionalmente y analizado. Thomas Hobbes, David Hume y Adam Smith, pero también nos vienen a la cabeza Claude-Adrien Hélvétius y el Baron Paul-Henri Dietrich d'Holbach. Otros pueden argumentar que no existe una naturaleza humana fija (Jean-Jacques Rousseau), o que incluso si la hubiese, ésta sería irrelevante para determinar qué es lo más esencial de nosotros en cuanto que humanos (Immanuel Kant): esto es, nuestra capacidad para formular y vivir de acuerdo a principios universalizables. Aun así, otros pueden repudiar la psicología empírica, la antropología filosófica y la ética racionalista y mantener que lo que resulta universal respecto a la condición humana es el hecho de que estamos condenados a elegir por nosotros mismos y a crear significado a través de nuestras acciones en un mundo vacío de estos estándares y valores. Aunque muchos universalistas filosóficos son esencialistas, no necesitan serlo. Como muestra el ejemplo de Jean-Paul Sartre, pueden ser también existencialistas.

2. Universalismo en los debates filosóficos contemporáneos ha acabado significando, de modo más prominente, una estrategia justificatoria. Hermeneutas, contextualistas fuertes, escépticos posmodernos y posestructuralistas, todos cuestionan el si puede haber una razón filosófica imparcial, objetiva y neutral; todos sostienen que las estrategias de justificación —a las que consideran pretensiones de objetividad filosófica - están atrapadas dentro de sus horizontes históricos y sujetas a corrientes de poder cultural, social y psicológico que apenas son reconocidas (cf. Michel Foucault, Jean-François Lyotard, y el joven Jacques Derrida).

En oposición a estos críticos contextualistas se encuentran los «universalistas justificatorios», la mayoría de los cuales no son esencialistas: algunos contemplan muy pocas creencias fundamentales sobre la psicología y la naturaleza humana; pero todos comparten y defienden creencias fuertes respecto al contenido normativo de la razón humana, esto es, sobre la validez de los procedimientos de investigación, prueba y cuestionamiento que han sido el legado cognitivo de la filosofía occidental desde la Ilustración. Imparcialidad,

${ }^{20}$ He desarrollado una primera versión de este análisis en The Claims of Culture. Equality and Diversity in the Global Era (Princeton and Oxford: Princeton University Press, 2002), 26-28. 
verificación intersubjetiva de resultados, argumentos y datos, consistencia en las creencias, y auto reflexividad son las condiciones mínimas de este contenido normativo (Karl Otto-Apel, Jürgen Habermas, Hilary Putnam, Robert Brandom, John Rawls y muchos otros so en este sentido «universalistas justificatorios»).

3. Universalismo, argumentan otros, no se trata primariamente de un término referido a la investigación cognitiva; posee además, de un modo igualmente relevante, un significado moral. Lo definiría como el principio de que todos los seres humanos, independientemente de su raza, género, orientación sexual, capacidades físicas o psíquicas, trasfondo cultural, étnico, lingüístico o religioso, tienen derecho a igual respeto moral. La pregunta difícil en la ética filosófica sigue siendo la de si este universalismo moral sin comprometerse con un universalismo cognitivista, tanto en el sentido del universalismo esencialista como del justificatorio.

4. Finalmente, el universalismo puede ser entendido en términos jurídicos. Muchos de quienes se declaran escépticos respecto a la posibilidad de proporcionar una descripción definitiva de la naturaleza humana y de la racionalidad puede que, sin embargo, insten a que las siguientes normas y principios deban ser respetados por todo sistema legal y político con pretensiones de legitimidad: todos los seres humanos tienen derecho a unos derechos humanos básicos, afirman estos universalistas jurídicos, incluyendo, como mínimo, los derechos a la vida, libertad, seguridad e integridad corporal, a alguna forma de posesión y propiedad personal, proceso debido ante la ley, libertad de expresión y asociación, incluyendo libertad de religión y conciencia. Algunos añadirían derechos socioeconómicos, como el derecho a trabajar, atención médica, minusvalía, y servicios a la tercera edad a esta lista; otros insistirían en incluir derechos de autodeterminación cultural y democrática ${ }^{21}$.

Defenderé que cualquier justificación política de los derechos humanos, esto es, el proyecto del universalismo jurídico, presupone recurrir a un universalismo justificatorio. El objetivo de la justificación, a su vez, no puede avanzar sin el reconocimiento de la libertad comunicativa del otro, esto es, de derecho del otro de aceptar como legítimas sólo aquellas reglas de acción de

21 La defensa de Richard Rorty de un «liberalismo burgués postmoderno» encaja dentro de este paradigma, como también lo hacen las numerosas intervenciones de Jacques Derrida en contra del apartheid y a favor de las minorías y los derechos civiles en le década anterior a su muerte. Son todos intentos de disociar lo «justo» de lo «bueno», y de distinguir lo que denomino como «universalismo jurídico» del esencialismo, tanto cognitivo como moral. El universalismo, tal como defienden, puede ser político sin ser metafísico. Cf. Richard Rorty, «Postmodernist Bourgeois Liberalism», Journal of Philosophy 80 (1983): 583-89; R. Rorty, «Human Rights, Rationality and Sentimentality», en On Human Rights: The Oxford Amnesty Lectures 1993, editado por Stephen Shute y Susan Hurley (New York: Basic Books, 1993), 11-34. Ver también Jacques Derrida, «Declarations of Independence», New Political Science (Summer 1986): 6-15. 
cuya validez ha resultado convencida con razones. El universalismo justificatorio descansa por tanto en el universalismo moral, por ejemplo, igual respeto por el otro en tanto que un ser capaz de libertad comunicativa. El universalismo justificatorio, de todos modos, no necesita presuponer una teoría detallada de la naturaleza humana o una cosmovisión comprehensiva moral, religiosa o científica: bastará con una descripción de la agencia humana en términos del otro «generalizado» y «concreto». Esto significa que el universalismo jurídico es incoherente sin una defensa del universalismo moral. De todos modos, éstas no son relaciones de «implicación». El universalismo moral no implica o dicta una lista específica de derechos humanos más allá de la protección de la libertad comunicativa de la persona; ni tampoco lo hace el universalismo justificatorio. Pero sin el reconocimiento de esta libertad comunicativa, la tarea de justificación en sí carece de significado. Todavía persistirán diferencias filosóficas en la articulación del contenido de este reconocimiento. Lo distintivo de mi posición radica en la interpretación de esta libertad comunicativa en relación con el «derecho a tener derechos».

\section{IV.}

Recordemos la provocativa afirmación de Alasdair MacIntyre: «La mejor razón para afirmar de un modo tan tajante que no existen tales derechos, es precisamente del mismo tipo que la mejor que tenemos para afirmar que no hay brujas, o la mejor razón que poseemos para afirmar que no hay unicornios: el fracaso de todos los intentos de dar buenas razones para creer que tales derechos existen» ${ }^{22}$. Haciéndose eco de la famosa ocurrencia de Jeremy Bentham de que la creencia en derechos naturales era un «sinsentido sobre zancos» ${ }^{23}$, MacIntyre da voz a una larga tradición de escepticismo hacia el discurso de los «derechos naturales», «derechos humanos», o «derechos básicos». Estas críticas se basan en un error que consiste en identificar los derechos humanos con el imaginario social de los primeros pensadores burgueses ${ }^{24}$. Históricamente, el amplio uso de términos como «propiedad» y «apropiado» (property/propriety) para designar los derechos en general ha servido para demarcar una esfera de exigencias y pretensiones individuales y les otorgó un

22 A. MacIntyre. After Virtue (London: Duckworth, 1981), 67. Cf. Jeremy Bentham: «Derecho, el derecho sustantivo, es el hijo de la ley; de leyes reales se derivan derechos reales; pero de leyes imaginarias, de la «ley natural» [sólo pueden derivarse] «derechos imaginarios». Jeremy Bentham. «Anarchical Fallacies». In The Works of Jeremy Bentham, vol. 2, ed. John Bowring (Edinburgh and London: W. Tait, 1843), 523.

23 Jeremy Bentham, «Anarchical Fallacies», p. 501.

24 Para un análisis cuidadoso de las contradicciones en las que cae la propia apelación de MacIntyre a la razón, ver Rainer Forst, Contexts of Justice. Political Philosophy beyond Liberalism and Communitarianism, trans. by John M. Farrell (Berkeley and Los Angeles: University of California Press, 2002), 200-15. 
aspecto de inviolabilidad ${ }^{25}$. Al mismo tiempo, este lenguaje ha viciado la discusión sobre los derechos hasta nuestros días.

No necesitamos ni repetir la falacia naturalista ni el uso paradigmático de la propiedad para defender pretensiones de derechos. Voy a argumentar que las pretensiones de derechos son generalmente de la siguiente forma: "Yo puedo justificar ante ti con buenas razones que tú y yo debemos respetar la exigencia recíproca de cada uno de actuar en ciertas formas y de no hacerlo en ciertas otras, y de disfrutar de ciertos recursos y servicios». Algunas exigencias de derechos son sobre libertades, esto es, de hacer o de abstenerse de hacer ciertas cosas sin que nadie más tenga una exigencia moral que me obligue a actuar o a abstenerme de hacerlo de ciertas formas. Los derechos sobre libertades generan obligaciones de abstención. Otras exigencias de derechos son sobre recursos. Estos derechos, como el derecho a una educación básica o a vecindarios seguros, por ejemplo, implican obligaciones por parte de otros sean estos individuos o instituciones, de actuar en ciertas formas y de proporcionar ciertos bienes materiales. Tal como Jeremy Waldrom observa, estos derechos desembocan en «una cascada de obligaciones» (cascading obligations) ${ }^{26}$.

Para la tradición del constructivismo moral kantiano, las pretensiones de derechos no se refieren a lo que «existe;» por el contrario, nos preguntamos si nuestras vidas en común, dentro, fuera y entre entidades políticas, no deben ser guiadas por inmunidades mutua y recíprocamente garantizadas, constricciones sobre acciones, y por un acceso legítimo a ciertos bienes y recursos. Los derechos no son sobre lo que existe sino sobre el tipo de mundo en el que debemos razonablemente desear vivir.

En su Metafísica de las Costumbres Kant proponía que existe un derecho básico: «cada acción que por sí misma o por su máxima, permite la libertad de cada voluntad individual de coexistir con la libertad de todas las demás de acuerdo con una ley universal es correcta (gerecht) ${ }^{27}$. Debemos tener en cuenta que la formulación de Kant no se refiere a una lista de derechos básicos de la que se afirma que es previa a la voluntad del soberano republicano. Más bien, este principio establece cómo puede llegar a existir un orden jurídico-civil que estuviese en conformidad con la ley moral. El «principio de dere-

25 Richard Tuck, Natural Rights Theories (Cambridge: Cambridge University Press, 1979); ver también Anthony Pagden, «Human Rights, Natural Rights, and Europe's Imperial Legacy», para una buena exposición histórica de la evolución del discurso de los derechos, que sin embargo evita apoyar o denunciar el eurocentrismo, en Political Theory 31 (April 2003): 171-99.

26 Jeremy Waldron. «Introduction», Theories of Rights (Oxford: Oxford University Press, 1984), p. xxx. También he encontrado de mucha utilidad, Matthew Noah Smith, «The Normativity of Human Rights» (manuscrito proporcionado por el autor).

27 Immanuel Kant. The Metaphysics of Morals [1797], trad. y editado por Mary Gregor. En Cambridge Texts in the History of Political Thought (Cambridge: Cambridge University Press, 1996), 133. 
cho», a igual que la tradición del discurso de los derechos naturales, afirma básicamente que sólo es legítimo aquel orden político que se basa en un sistema de leyes generales que vincula la voluntad de cada uno de un modo igual. Generalidad, reciprocidad formal e igualdad son características del «principio del derecho». Tu libertad en tanto que ser moral sólo puede ser restringida por razones que pudiesen ser aplicadas general y recíprocamente a cada uno. Una comunidad política basada en el principio del derecho te respeta en tanto que ser moral.

Una justificación discursivo-teorética del principio del derecho diferiría de la de Kant de las siguientes formas: en lugar de preguntar qué podría desear, sin contradecirse a sí mismo, que fuese una ley universal para todos, en la ética del discurso preguntamos: ¿qué normas y acuerdos institucionales normativos podrían ser considerados válidos por todos aquellos que fuesen afectados por ellos si fuesen participantes en el tipo especial de argumentación moral que llamamos discurso? (T. A. McCarthy). El énfasis se desplaza ahora desde lo que cada uno podría desear que fuese válido para todos a través de un experimento mental, a aquellos procesos justificatorios a través de los que tú y yo en diálogo debemos convencernos mutuamente de la validez de ciertas normas, por las que entiendo «reglas generales de acción».

¿Cómo podemos entonces justificar el hablar de derechos humanos sin caer ni en las trampas de la falacia naturalista ni en las del individualismo posesivo? Mi respuesta es: "para ser capaz de justificar ante ti por qué tú y yo debemos actuar de cierto modo, debo respetar tu capacidad de aceptar o rechazar razones cuya validez tú aceptas o rechazas. Pero respetar tu capacidad de aceptar o rechazar razones cuya validez tú evalúas significa para mí el respetar tu capacidad para la libertad comunicativa». Estoy asumiendo aquí que todos los seres humanos que son hablantes de un lenguaje natural son capaces de libertad comunicativa, esto es, de decir «sí» o «no» a unos enunciados cuyas pretensiones de validez comprenden y de acuerdo a las cuales pueden actuar. Los derechos humanos son por lo tanto, principios morales que protegen el ejercicio de tu libertad comunicativa y que requieren su materialización en forma legal.

Ciertamente, el ejercicio de libertad comunicativa es también un ejercicio de agencia, de formular qué metas y fines deseamos perseguir, y cómo llevarlo a cabo. A diferencia de las teoría de los derechos humanos centradas en el agente, que son sin embargo todavía las más comúnmente aceptadas, en el modelo discursivo-teorético procedemos desde una concepción del ser humano como un individuo incardinado en contextos de comunicación así como de interacción. La capacidad de formular objetivos para la acción no es previa a la capacidad de justificar estas metas con razones ante otros. Las razones para la acción no son sólo fundamentos que me motivan, son también justificaciones de mis acciones en la medida en que yo me proyecto como un «hacedor» sobre un mundo social que comparto con otros, y a través del cual otros me 
reconocen en tanto que una persona capaz de, y responsable de, ciertos cauces de acción. Agencia y comunicación son dos caras de la misma moneda: sólo me conozco a mi mismo como un agente porque puedo anticipar el ser parte de un espacio social en el que otros me reconocen como el iniciador de ciertos actos y el enunciador de ciertas palabras. El punto débil de todas las formulaciones de los derechos humanos centradas en el agente es que lo abstraen de la incardinación social de la agencia en estos contextos compartidos de habla y acción, y en su lugar se centran en el agente aislado como el sujeto privilegiado para razonar sobre los derechos ${ }^{28}$.

Primero y ante todo, en tanto que ser moral capaz de libertad comunicativa, posees un derecho a tener derechos fundamental. Para ejercer la libertad comunicativa es preciso que se respeten tu capacidad para una agencia incardinada, tu capacidad para la comunicación así como para la acción. Es necesario que se te reconozca como un miembro de una comunidad humana organizada en la que tus palabras y tus actos te sitúen dentro de un espacio social de interacción y comunicación. Posees un «derecho», es decir, una exigencia moral de ser reconocido por otros como «una persona portadora de derechos» con una demanda legítima de una carta de derechos legalmente instituida ${ }^{29}$. Los otros sólo pueden restringir tu libertad en tanto que ser moral a través de razones que satisfagan las condiciones de formalidad, generalidad y reciprocidad para todos.

El derecho a tener derechos implica, además, el reconocimiento de tu propia identidad como otro generalizado al tiempo que como uno concreto ${ }^{30}$. Si te reconozco como un ser con derecho a derechos sólo porque eres como yo, entonces estoy negando tu individualidad fundamental, que implica tu ser diferente. Si me niego a reconocerte como un ser con derecho a derechos por tu marcada otredad respecto a mí, entonces estoy negando nuestra común humanidad.

El punto de vista del «otro generalizado» requiere que contemplemos a todos y cada uno de los individuos como seres que tienen los mismos derechos y deberes que deseamos adscribirnos a nosotros mismos. Al asumir este punto de vista hacemos abstracción de la individualidad y de la identidad concreta del otro. Asumimos que el otro, al igual que nosotros mismos, es un ser que posee necesidades concretas, deseos y afectos, pero lo que constituye su dignidad moral no es lo que nos diferencia a unos de otros, sino lo que no-

28 Éste es el mayor defecto en la formulación de Griffit, que no deja de ser instructiva, «Discrepancies between the Best Philosophical Account of Human Rights and the International Law of Human Rights», The Presidential Address, Proceedings of the Aristotelian Society 101 (2001): 1-28; pp. 4 ss.

29 Para un análisis de los dos significados del «derecho a tener derechos», en términos de sus componentes moral y jurídico-civil, ver Seyla Benhabib, The Rights of Others. Aliens, Residents and Citizens (Cambridge: Cambridge University Press, 2004), 56-61.

30 Ver Seyla Benhabib, Situating the Self. Gender, Community and Postmodernism in Contemporary Ethics (London and New York: Routledge, 1992), 35-37. 
sotros, en tanto que seres hablantes, actuantes y situados, tenemos en común. Nuestra relación con el otro se rige por las normas de la igualdad formal y la reciprocidad: cada uno tiene derecho a esperar de nosotros lo que podemos esperar de él o ella. Al tratarte de acuerdo con estas normas, ratifico en tu persona los derechos de la humanidad y ostento una exigencia legítima de que tú harás lo mismo respecto a mí.

El punto de vista del «otro concreto», en contraste, requiere que veamos a todos y cada uno de los seres como un individuo con una constitución afectivo-emocional, una historia concreta, una identidad tanto colectiva como individual. A asumir este punto de vista, ponemos entre paréntesis lo que constituye nuestro repertorio común y nos centramos en la individualidad. Nuestra relación con el otro se gobierna por las normas de equidad y de complementaria reciprocidad. Nuestras diferencias en este caso, más que excluirse se complementan. Al tratarte de acuerdo con estas normas, no sólo ratifico tu humanidad, sino tu individualidad humana. Si el punto de vista del otro generalizado expresa la norma del respeto, el del otro concreto anticipa experiencias de altruismo y solidaridad.

Los conceptos del otro generalizado y del otro concreto no describen la naturaleza humana; son más bien articulaciones fenomenológicas de la experiencia humana. Admito que el punto de vista del otro generalizado, en la forma plenamente universalista que le he dado, presupone las experiencias igualitarias de la modernidad. No defiendo, al modo hegeliano, que estas concepciones sean los productos-finales del curso de la historia. Más bien son contestables, frágiles experiencias a través de las cuales el punto de vista del otro generalizado, extensivo a «toda la humanidad», se convierte en una posibilidad práctica, aunque ciertamente, no en una realidad política.

Este reconocimiento recíproco de cada uno como seres que poseen el «derecho a tener derechos» implica luchas políticas, movimientos sociales y procesos de aprendizaje dentro y a través de las clases, géneros, naciones, grupos étnicos y credos religiosos. Éste es el auténtico significado del universalismo: el universalismo no consiste en una esencia o naturaleza humana que se nos dice que todos tenemos o poseemos, sino más bien en experiencias de establecer una comunalidad a través de la diversidad, conflicto, división y lucha. El universalismo es una aspiración, un objetivo moral por el que pelear; no es un hecho, una descripción del modo en que el mundo es ${ }^{31}$.

31 Para una sopesada posición que yo también asumo, cf. Heiner Bielefeldt: «La historia de los derechos humanos en Occidente no consiste en un modelo vinculante que nos permite realizar predicciones sobre las expectativas de os derechos humanos en otras partes del mundo... ...En su lugar, la historia de os derechos humanos en Occidente nos brinda un ejemplo - no el paradigma per se sino meramente un ejemplo — de los diversos obstáculos, confusiones, procesos de aprendizaje, logros y fracasos en la prolongada lucha por los derechos humanos». En «"Western" versus "Islamic" Human Rights Conceptions?: A Critique of Cultural Essentialism in the Discussion of Human Rights», Political Theory 28 (February 2000): 90-121; pp. 101-102. 
Permítaseme enfatizar cómo difiere de otras esta justificación de los derechos humanos a través de esta formulación discursivo-teorética de la libertad comunicativa. En primer lugar, la justificación de los derechos humanos se contempla como una práctica dialógica que no se enreda en la metafísica de las teorías de los derechos naturales o de los yoes del individualismo posesivo. Esta justificación de los derechos humanos también difiere de formulaciones relativas al agente, porque en éstas se asume que los derechos humanos son condiciones de posibilidad para el ejercicio de la agencia bajo alguna descripción. Esto deja entonces sin respuesta la cuestión de por qué la pretensión de que cierta condición u otra resulta esencial para el ejercicio de $t u$ agencia impone una obligación moral sobre $m i$ de respetar esa exigencia. En contraste, en el modelo discursivo argumentamos que el reconocimiento de tu derecho a tener derechos es la auténtica precondición de que tú seas capaz de contestar o aceptar mi exigencia de derechos primera. Mis necesidades específicas del agente peden servir como una justificación para $t i$ sólo si presupongo que tus necesidades especificas del agente pueden igualmente servir como justificación para mí. Y esto significa que tú y yo hemos reconocido el derecho a tener derechos de cada uno.

¿No prueba esta justificación discursivo-teorética de los derechos humanos demasiado o demasiado poco? ¿No dependen mis formulaciones de alguna comprensión de qué constituyen las «buenas razones» en los discursos? Y seguramente, añadirá el contextualista, estas comprensiones compartidas es difícil que no sean controvertidas, así que tu estrategia de justificación se enreda en la circularidad. Presupone una comprensión de las «buenas razones» de modo que descarta puntos de vista morales incompatibles con el no-reconocimiento de la libertad comunicativa. Para hacer frente a esta seria objeción, permitidme primero la observación de que los discursos, a diferencia de la negociación, la persuasión, el lavado de cerebros, o la manipulación coercitiva, dependen de ciertas condiciones formales de la conversación: éstas son, la igualdad de cada interlocutor para participar en la comunicación, así como para iniciarla, su derecho simétrico a actos de habla y a la reciprocidad de los roles comunicativos: cada uno puede preguntar y responder, aportar nuevos elementos a la agenda, e iniciar la reflexión sobre las reglas del propio discurso. Estas precondiciones formales, que requieren ellas mismas reinterpretación dentro del proceso discursivo, imponen ciertas constricciones necesarias respecto a los tipos de razones que se tomarán como aceptables dentro de los discursos, pero éstas nunca pueden ni se les debe exigir que proporcionen suficiente fundamento para lo que constituyen «buenas razones». De hecho, aquí tenemos una circularidad, mas no un círculo vicioso. Se trata de la circularidad hermenéutica de la razón práctica sobre la que ya había observado Aristóteles en su Ética que constituye un rasgo esencial de todo razonamiento en moral y política: tenemos que asumir siempre cierta comprensión de la igualdad, la reciprocidad y la simetría para ser capaces de acotar el mo- 
delo discursivo en primer lugar, pero cada uno de estos términos normativos están entonces abiertos a la justificación reflexiva, a la validación recursiva dentro del discurso en sí. Esta validación recursiva de las precondiciones del discurso ha sido mal entendida por muchos como un indicador de un círculo vicioso. Estos cargos ignoran la estructura hermenéutica de la razón práctica y desean que proceda como si fuese la razón teorética — a partir de primeras premisas no discutidas.

Esta limitación en el rango de lo que puede contar o no como «buenas razones» en términos de las condiciones necesarias de estructuras discursivas recursivamente validadas todavía no convencerá a algunos ${ }^{32}$; sin embargo, me permito enfatizar que la libertad comunicativa es lo que hace posible la práctica de justificación normativa, ya que si los seres humanos no pueden asentir a, o rechazar las exigencias de cada uno en base a razones cuya validez puedan evaluar, entonces no puede haber tarea justificatoria en absoluto. Incluso si las razones que invocamos en esta práctica son utilitaristas o kantianas, nietzscheanas o cristianas, al hacerlo debemos siempre previamente presuponer la capacidad de nuestro interlocutor de asentir o de disentir de nuestras exigencias sobre la base de razones cuya validez ella comprende. El «universalismo justificatorio» se encuentra en el corazón de la razón en tanto que tarea de dar-razón del mismo modo que lo es el reconocimiento del otro en tanto que un ser capaz de libertad comunicativa y del derecho a tener derechos.

La motivación para los discursos morales surge cuando se quiebran las certezas de nuestro mundo de vida a través del conflicto, el disenso y el desacuerdo, cuando existe conflicto además de controversia, miseria así como falta de solidaridad. Estos discursos no son sólo hipotéticos experimentos mentales o salas de juntas en las que podemos elegir el entrar o salir a voluntad; son diálogos reflexivos cuya necesidad emerge de los auténticos problemas reales de nuestros mundos de vida. Sólo cuando desaparecen las certidumbres cotidianas es cuando asumimos la actitud del distanciamiento crítico y reflexivo que resulta esencial para los discursos. En este sentido Husserl está en lo

32 Me gustaría agradecer a Richard Bernstein por su insistencia sobre este punto. En The Claims of Culture me ocupaba de esta cuestión desde un tipo de democracia deliberativa y distinguía entre la «sintaxis» y la «semántica» del dar razones públicas. Las razones, sugería yo, contarían como buenas porque podrían ser consideradas como en el mejor interés de todos, considerados como seres morales y políticos». Y someter a escrutinio si X o Y — una política, una ley, un principio de acción - consiste «en el mejor interés de todos», significaría "que hemos establecido $\mathrm{X}$ o Y a través de procesos de deliberación pública en los que todos los afectados por estas normas y medidas políticas toman parte como participantes en un discurso». Benhabib, The Claims of Culture, pp. 140 ss. Afirmaba que no existe forma de conocer previamente qué exigencias o perspectivas semánticamente específicas pueden contar como «buenas razones». Lo que la ética del discurso, así como la democracia deliberativa modelada según la ética del discurso descarta, son ciertos tipos de razones - éstas son las que no pueden ser sintácticamente generalizables. 
cierto: hay una conexión intrínseca entre el compromiso con la razón como forma de vida fundada en prácticas contingentes de dar-razón y justificación y la concepción de la persona humana como un ser libre que tiene derecho a ser respetado.

Existe un vínculo inquebrantable, por lo tanto, entre la razón entendida como una tarea de justificación, y la justificación de los derechos humanos. El universalismo justificatorio presupone el universalismo moral - el respeto por el otro en tanto que ser capaz de libertad comunicativa- . No estoy fundamentando el derecho a tener derechos sobre la razón humana, que la tradición iusnaturalista consideraba como una expresión de la divinidad en los seres humanos. Más bien, he argumentado que el derecho a tener derechos y el derecho moral de los seres humanos a ser considerados como seres con pretensiones de derechos jurídico-políticos son condiciones de posibilidad para el ejercicio de la libertad comunicativa.

Los derechos humanos y los diversos documentos de derecho público definen tanto un mínimo que debe ser mantenido, como un máximo al que se debe aspirar entre seres humanos que han reconocido el derecho a tener derechos de cada uno. Siempre habrá debate sobre su significado y su amplitud; por tanto cualquier lista de ellos que proporcionemos es necesariamente incompleta. Las nuevas luchas morales, políticas y culturales producirán derechos que deberán ser añadidos a la lista y extenderán el máximo al que los seres humanos pueden aspirar. Por ejemplo, los desarrollos tecnológicos en la clonación humana, la terapia génica y la manipulación genética es probable que conduzcan a algunos derechos básicos que protejan la integridad biológica de los seres humanos y de la especie en el futuro próximo ${ }^{33}$. Precisamente porque emergen de estas luchas y procesos de aprendizaje, los documentos de los derechos humanos no pueden meramente incorporar un «consenso solapado» o «condiciones mínimas de legitimidad»; éstos dan voz a las aspiraciones de una humanidad profundamente dividida al establecer «un estándar común de realización para todos los pueblos y todas las naciones» (Declaración Universal, Preámbulo).

¿Cómo puede uno realizar la transición desde estas consideraciones enormemente abstractas y formales sobre el derecho a tener derechos a los regímenes de derechos específicos, sistemas legales, cartas, y convenciones de las entidades políticas existentes? ¿Y qué sucede con la forma legal de los derechos humanos? ${ }^{34}$ Tanto en la jurisprudencia como en la filosofía moral ha

33 Ver las muy instructivas reflexiones de Norberto Bobbio, «Human Rights Now and in the Future», en The Age of Rights, trad. Allan Cameron (London: Polity Press, 1996), 12-32.

34 Para una posición que diferencia fuertemente entre las dimensiones moral y ética de los derechos humanos y su articulación legal, ver Amartya Sen, «Elements of a Theory of Human Rights», Philosophy and Public Affairs, p. 319. Sen desea considerar a los derechos humanos como «demandas fundamentalmente éticas» que se correlacionan con la «significatividad de las libertades que forman el objeto de estos derechos. Aunque evita una ofrecer una enumera- 
habido dos posiciones dominantes que responden a esta pregunta: el derecho natural contra el positivismo jurídico. La posición del derecho natural puede contar a Aristóteles y Platón, a los estoicos así como a Santo Tomás de Aquino, los teóricos modernos del contrato social, como Locke y Rousseau, así como a Leo Strauss, entre sus defensores. Ellos argumentan que no puede considerarse legítimo ningún orden político o legal que no suscriba, respete o consagre en su constitución ciertos derechos que son exigibles por los seres humanos en tanto que seres humanos y que son además inalterables e irrescindibles. En el lenguaje del constitucionalismo moderno, estos derechos son «fundamentales».

El positivismo jurídico, una posición compleja que algunos rastrean hasta sofistas como Trasímaco, hasta Maquiavelo, o H.L.A. Hart, así como a Carl Schmitt, argumentan que los sistemas legales no son susceptibles de ser objeto de juicios basados en estándares de articulación extralegales — sean estos morales, metafísicos, naturalistas o científicos-. Cualquier sistema legal, en la medida en que es una articulación coherente de normas, lleva en sí sus propios estándares de enjuiciamiento, evaluación, subordinación y subsunción - en breve, sus propias reglas de reconocimiento que lo hacen funcionar como el sistema legal que es- - La idea de normas afianzadas, tal como se consideran las del derecho natural, y que se supone que preceden a este sistema legal, son ininteligibles desde este punto de vista.

El lenguaje de los derechos humanos se extiende sobre esta división. El discurso de las democracias, en particular, se ve necesariamente atrapado en esta tensión generada por la dimensión de validez de los derechos humanos que trasciende el contexto y la comunidad por una parte, y las especificidades formadas históricamente, generadas culturalmente y socialmente modeladas de las

ción exhaustiva de estas libertades, para Sen las libertades son realizaciones de capacidades, tanto en el sentido de oportunidades y procesos requeridos para el despliegue de las capacidades. «Más bien la libertad, en su forma de capacidad, se centra en la oportunidad de lograr combinaciones de funciones...» (334). Al situar los derechos humanos de un modo tan central dentro de una teoría ética de la libertad y las capacidades, Sen deja de lado la historia política del concepto de derechos, que siempre ha estado íntimamente relacionada a exigencias de legitimidad y gobierno justo. Los derechos no se reducen a fuertes titularidades morales que se acumulan sobre los individuos, tienen que ver con exigencias de justicia y legitimidad que enmarcan nuestra existencia colectiva. No podemos reducir los derechos únicamente al lenguaje de la corrección moral. Violar un derecho no es lo mismo que infligir un daño moral a una persona. Podemos realizar esto último sin necesidad de realizar lo primero; al tiempo que algunas violaciones de derechos, si bien no todas, pueden ser formas de daño moral. Cuando te humillo delante de tu familia, amigos y seres queridos, por ejemplo, inflijo un daño moral sobre tu dignidad como persona; pero no por ello he violado tu derecho humano a la dignidad, algo que sí estaría haciendo si te sometiese a tortura y a otras formas de «castigo cruel e inusual». Toda violación de los derechos humanos básicos, por el contrario, que violan la libertad comunicativa de la persona, también inflige daños morales. No alanzo a ver que podamos hace en la formulación de Sen una diferenciación tan necesaria entre «daño moral» por una parte y «violación de derechos» por la otra. 
comunidades jurídico-civiles por la otra. El objetivo es no negar esta tensión, abrazando sólo una de estas alternativas morales, sino negociar su interdependencia re-situando o reiterando lo universal en contextos concretos. Éste es un proyecto que he denominado «universalismo interactivo» en Situating the Self e «iteraciones democráticas» en obras subsiguientes ${ }^{35}$. Es alrededor de la negociación de la unidad y la diversidad de los derechos humanos, esto es, la relación entre su núcleo moral y su forma legal, donde se hacen visibles las diferencias más relevantes entre mi enfoque y otras posiciones contemporáneas.

Si los derechos humanos encarnan principios que necesitan contextualización y especificación en la forma de normas legales, entonces debemos preguntar de qué modo se va a modelar este contenido legal. El derecho a tener derechos parece bastante abstracto y formalista, e incomodará, cuando menos, a muchos teóricos del derecho natural. La razón se debe a que se abstiene de prescribir el contenido que correspondería a cada individuo en materia de derechos civiles y políticos, una vez que el derecho a tener derechos fuese reconocido. En respuesta a esta consideración, una aproximación posible puede ser la de proceder desde el derecho a tener derechos, del que ya he defendido que protege la libertad comunicativa de la persona, a las normas de igual respeto y consideración, y de este modo derivar posteriormente una lista concreta de derechos humanos. Los derechos humanos encontrarían entonces su lugar en la filosofía moral.

Los derechos humanos básicos, aunque se basan en el principio moral de la libertad comunicativa de la persona, son también derechos legales, por ejemplo, derechos que requieren su positivización en un marco legal específico. Como ha observado Ronald Dworkin, los derechos humanos están a caballo entre la moralidad y la justicia; nos permiten juzgar la legitimidad de la ley ${ }^{36}$. El contenido fundamental de los derechos humanos formaría parte también de cualquier concepción del derecho a tener derechos: incluirían como mínimo los derechos a la vida; la libertad (incluyendo el vivir libre de esclavitud, servidumbre, ocupación forzosa, así como de violencia y esclavitud sexuales) ${ }^{37}$; a alguna forma de propiedad personal; y a igual libertad de

35 Ver Seyla Benhabib, Another Cosmopolitanism. Sovereignty, Hospitality, and Democratic Iterations, The Berkeley Tanner Lectures, con respuestas de Jeremy Waldron, Bonnie Honig y Will Kymlicka, editado por Robert Post (New York and London: Oxford University Press, 2006).

36 Ver el ensayo clásico de Ronald Dworkin, «Taking Rights Seriously» (1970), en Taking Rights Seriously (Cambridge, MA: Harvard University Press, 1978), pp. 184 ss.

37 Dado que yo considero a los individuos como otros «generalizados» y «concretos», el tener en cuenta su corporalidad y personificación, la protección de su integridad corporal en 
pensamiento (incluyendo religión), expresión, y asociación. Más aún, la libertad requiere también los recursos para el «igual valor de la libertad» (Rawls) a través de la garantía de los bienes socioeconómicos, que incluyen la adecuada provisión de alimentación básica, cobijo y educación.

El acuerdo sobre este contenido central deja todavía sin resolver muchas de las dificultades filosóficas: si estamos de acuerdo en la centralidad de un principio como el de la «libertad de expresión religiosa» debemos también aceptar que las religiones minoritarias también tienen legítimas demandas de derechos a la expresión pública en igualdad con la mayoría, tal como he argumentado, o ¿podemos acaso mantener que la libertad de expresión religiosa es compatible con ciertas restricciones razonables sobre su ejercicio, tal como Rawls ha defendido? Es en este punto que el derecho humano al autogobierno se vuelve crucial y ésta es la razón por la que yo argumentaría, en contra de Rawls, que se trata de un derecho fundamental. Sin el derecho al autogobierno, ejercitado a través de los canales políticos y legales apropiados, no podemos justificar como legítimo el grado de variación en el contenido de los derechos humanos. Si la dificultad en la concepción de Martha Nussbaum sobre los derechos humanos radica en que en ella no se diferencia entre la justificación filosófica de los derechos humanos y su plasmación legal (ver páginas anteriores), la debilidad de la posición minimalista rawlsiana sobre los derechos humanos consiste en que uno está obligado a aceptar cualquier cosa que un régimen legal estipule que sea el contenido de los derechos humanos, siempre y cuando cumpla ciertos criterios mínimos propios de «una sociedad decente, bien-ordenada». Entre otras cosas, esto es compatible con la negación de la igual libertad religiosa, de expresión y asociación para las minorías así como con el rechazo al derecho al autogobierno democrático.

Ciertamente, las tradiciones jurídica, constitucionales así como del derecho consuetudinario de cada sociedad humana, la historia de sus interpretaciones sedimentadas, sus debates internos y desacuerdos darán forma a la articulación legal de los derechos humanos. Por ejemplo, mientras que la igualdad ante la ley es un principio fundamental para todas las sociedades que observan el imperio de la ley, en muchas sociedades como Canadá, Israel e India, esto es considerado como bastante compatible con inmunidades especiales y prerrogativas adscritas a individuos en virtud de su pertenencia a di-

tanto que personas, que están sexuadas de modo diferente, es un derecho humano importante. No sólo las mujeres están sometidas a violencia sexual, muchos gays también lo están; de todos modos, debido a su capacidad de quedarse embarazadas, la violencia y el sometimiento arbitrario contra las mujeres afecta a su personalidad y a su libertad comunicativa de una forma diferente que a los hombres gays. El punto importante es tener presente los diferentes tipos de violencia a los que uno puede ser sometido como resultado de la diferencia sexual e incorporarlas dentro de nuestra comprensión de los derechos humanos. Por ejemplo, muchos gobiernos, incluidos los EE.UU. y Canadá, ahora reconocen y garantizan la legitimidad de la petición de asilo de las mujeres que escapan de la mutilación genital femenina. 
ferentes grupos culturales, políticos y religiosos ${ }^{38}$. Para sociedades como los EE.UU. y Francia, con concepciones de la ciudadanía más universalistas, estos arreglos multiculturales serían completamente inaceptables. Al mismo tiempo, en Francia y Alemania, la norma de la igualdad de género ha llevado a los partidos políticos a adoptar varias versiones del principio de la «paridad» - es decir, que las mujeres deben ocupar cargos públicos al cincuenta por ciento con los hombres, y que en las elecciones sus nombres deben ir en las listas de los partidos en igualdad de condiciones que los candidatos masculinos. En contraste, en los EE.UU. la igualdad de género está protegida por el título IX, que sólo se aplica para las grandes instituciones que reciben financiación federal. Los partidos políticos están excluidos de esta práctica. En otras palabras, existe un grado de variación legítimo incluso en la interpretación e implementación de un derecho tan básico como el de la «igualdad ante la ley». La legitimidad de este grado de variación depende de un modo crucial del principio de autogobierno y aquí es dónde yace lo distintivo de un enfoque basado en la libertad comunicativa. La libertad de expresión y de asociación no son únicamente derechos políticos de los ciudadanos cuyo contenido puede variar de una a otra comunidad política; son condiciones cruciales para el reconocimiento de los individuos en cuanto que seres que viven en un orden político, de cuya legitimidad han sido convencidos con buenas razones. Sólo cuando ha sido satisfecha esta condición podemos decir también que existe una legítima «unidad y diversidad» en los derechos humanos entre las sociedades políticas bien ordenadas.

Si no vemos a la gente meramente como sujetos a la ley sino también como creadores de la ley, entonces se puede decir que la contextualización e interpretación de los derechos humanos procede de procesos democráticos de opinión y formación de la voluntad públicos y libres. Esta contextualización, además de estar sujeta a varias formas del imperio de la ley y de tradiciones legales en diferentes países, adquiere legitimidad democrática en la medida en que es llevado adelante a través de la interacción entre las instituciones legales y políticas en espacios públicos libres en la sociedad civil. Cuando estos principios de derecho son apropiados por la gente como suyos, pierden su parroquialismo así como la sospecha de paternalismo occidental que llevan típicamente asociada. Llamaré a estos procesos de apropiación «iteraciones democráticas»».

Entiendo por iteraciones democráticas procesos complejos de argumentación pública, deliberación e intercambio a través de los que las demandas universalistas de derechos son contestadas y contextualizadas, invocadas y revocadas, positivizadas y posicionadas a través de instituciones legales y políticas, así como en las asociaciones de la sociedad civil.

38 Para una mayor elaboración, ver Benhabib, The Claims of Culture, especialmente cap. 5. 
En el proceso de repetición de un término o concepto, nunca nos limitamos a producir una simple réplica de su primera intención de uso o de su significado original: más bien, cada repetición es una forma de variación. Cada iteración transforma el significado, le añade matices, lo enriquece de las formas más sutiles. La iteración y repetición de normas y de cada aspecto del universo del valor, sin embargo, no es meramente un acto de repetición. Cada acto de iteración implica dar sentido a un original previamente aceptado dentro un contexto nuevo y diferente. $\mathrm{Al}$ antecedente se le otorga por lo tanto una nueva ubicación y significación a través de los usos y referencias subsiguientes. El significado se incrementa y transforma; igualmente, cuando la apropiación creativa de este original aceptado deja de tener sentido, entonces el original pierde a su vez la validez que le reconocíamos ${ }^{39}$.

Si las iteraciones democráticas son necesarias para que podamos juzgar la legitimidad de un abanico de variaciones en la interpretación de una exigencia de derecho, ¿cómo podemos valorar si ha habido iteración democrática en lugar de procesos demagógicos de manipulación o indoctrinación autoritaria? ¿No presuponen las iteraciones democráticas ciertos estándares de derechos para poder ser evaluadas con propiedad? Acepto la intuición de Jürgen Habermas de que «el principio democrático» establece que «sólo pueden pretender legitimidad aquellas regulaciones que puede lograr el asentimiento ( $\mathrm{Zus}$ timmung) de todos los ciudadanos en un proceso legislativo discursivo que ha sido legalmente constituido» ${ }^{40}$.

La «constitución legal de un procedimiento de legislación discursivo» sólo es posible en una sociedad que institucionaliza un marco comunicativo a través del cual los individuos, en tanto que ciudadanos o residentes, pueden participar en la formación de la voluntad y la opinión respecto a las leyes que van a regular sus vidas en común. El derecho a tener derechos no es sólo un derecho a condiciones de pertenencia, sino que implica el derecho a actuar y a opinar en la esfera pública de una comunidad política cuyas leyes gobiernan la existencia de uno. Sólo a través de la expresión pública de la opinión y de la acción puede concebirse a la persona humana como una criatura con capa-

39 Presento las iteraciones democráticas como un modelo para pensar la interacción entre las disposiciones constitucionales y la política democrática. Puede ser posible extender las iteraciones democráticas como un modelo para el «poder constituyente», así como para el acto fundacional. En este ensayo asumo que las iteraciones democráticas se tratan de cuestiones políticas ordinarias, en posición a la política constitucional; aunque defiendo que las formas de política ordinaria pueden encarnar formas de constitucionalismo popular, y pueden conducir a transformaciones constitucionales a través de procesos de adición. Mucho más tendría que decirse sobre las relaciones entre un análisis teorético-discursivo de las iteraciones democráticas y el liberalismo político, de lo que me permiten los límites de este ensayo. Ver las reflexiones finales de Rawls en su «Political Liberalism: Reply to Habermas», The Journal of Philosophy, 92 (March 1995), pp. 172 ss. Gracias a mi alumna Angélica Bernal por sus observaciones sobre este problema.

40 Jürgen Habermas. Between Facts and Norms. Contributions to a Discourse Theory of Law and Democracy, trad. William Regh (Cambridge, MA: The MIT Press, 1996), 110. 
cidad para interpretar ella misma exigencias de derechos ${ }^{41}$. Tener derechos no significa poseer un atributo físico como tener ojos verdes o un objeto como una camisa roja. Significa la capacidad de iniciar una acción u opinión que puede ser compartida por otros a través de una interpretación de la misma exigencia de derecho en sí. Hemos tenido una interpretación muy pasiva de la agencia implicada en la posesión de derechos. Los derechos humanos y los derechos de autogobierno están entrelazados. Aunque estos dos últimos no son idénticos, sólo a través de instituciones de autogobierno pueden los ciudadanos y residentes de una comunidad política articular distinciones justificables entre derechos humanos y derechos civiles y políticos, y juzgar el rango de sus variaciones legítimas.

La legitimidad democrática se remonta a principio de justificación normativa, aunque estos dos no son idénticos. Las iteraciones democráticas no alteran las condiciones de validez normativa de los discursos prácticos que han sido establecidos independientemente de ellos. Las iteraciones democráticas nos permiten juzgar como legítimos o ilegítimos los procesos de formación de la voluntad y de la opinión a través de los que las exigencias de derechos se contextualizan y contestan, expanden y revisan en las prácticas institucionales llevadas a cabo a la luz de estos criterios. Estos criterios de enjuiciamiento nos permiten distinguir un consenso fáctico de otro motivado racionalmente (ver sección IV).

$V I$.

Al mismo tiempo que Husserl contemplaba el panorama político-intelectual de una Europa que se precipitaba hacia una guerra mundial en 1935, la frágil institución de la Sociedad de Naciones se desplomaba debido a, entre otras cosas, a las hipocresías creadas por varios tratados sobre minorías y naciones sin estado que habían acompañado la desaparición de los imperios Austro-Húngaro, Ruso y Otomano, así como del Kaiserreich alemán. Para Husserl, la fe en la razón occidental, por fuerza, tenía que reemplazar la expectativa de que las estructuras institucionales pudiesen encarnar las relaciones entre razón y libertad, paz y justicia, de un modo más tangible. Así y todo, la Declaración Universal de 1948 y la era de los derechos humanos que le ha seguido refleja las experiencias de aprendizaje moral, no sólo de la humanidad occidental, sino de la humanidad en su totalidad. Los combates de las guerras mundiales no sólo se desarrollaron en el continente europeo sino también en las colonias, en África y Asia. Las luchas de liberación nacional y de antico-

41 Para una discusión de las tradiciones que, al margen del liberalismo, no reconocen que los individuos sean «fuentes de exigencias válidas originadas en sí mismas», ver Joshua Cohen, «Minimalism about Human Rights: The Most We Can Hope For?» p. 207. 
lonización del período posterior a la Segunda Guerra Mundial, a su vez, inspiraron principios de autodeterminación. Los documentos de derecho público de nuestro mundo - la DUDH; los diversos convenios internacionales sobre derechos humanos, y la Convención de Ginebra de 1961 en Relación con el Estatuto de los Refugiados y su Protocolo de 1967- se destilan de las luchas colectivas así como del aprendizaje común. Puede que resulte demasiado utópico llamarlos pasos de cara a una «constitución mundial», pero son más que meros tratados entre estados. Son documentos de derecho público global que, junto con otros desarrollos en el dominio de la lex mercatoria, están alterando el terreno del ámbito internacional. Son elementos constituyentes de una sociedad civil global y no meramente internacional. En esta sociedad civil global, los individuos no son portadores de derechos únicamente en virtud de su ciudadanía dentro de estados, sino en virtud de su humanidad sin excepción. Aunque los estados siguen siendo los actores más poderosos, el margen legítimo y legal para su actividad es cada vez más limitado. Necesitamos repensar la ley de los pueblos contra el trasfondo de esta emergente y frágil sociedad civil global, que está siendo constantemente amenazada por la guerra, la violencia y la intervención humanitaria. La menguante esfera pública mundial, al tiempo que incrementa los contactos a través de las culturas, también crea desconcierto sobre el modo de explicar sus profundas divergencias. He intentado proporcionar algunas respuestas filosóficas a estas perplejidades en esta exposición.

Existe una relación fundamental entre los complejos diálogos culturales ${ }^{42}$ entre gentes en una sociedad civil global y los procesos de iteración democrática. Sólo cuando los miembros de una sociedad se pueden implicar en un diálogo libre e irrestricto sobre su identidad colectiva en esferas públicas libres es posible que desarrollen narrativas de auto-identificación que revelen re-apropiaciones fluidas y creativas de sus propias tradiciones. En contraste, los discursos totalizadores de «nuestra» cultura opuesta a «la suya» pretenden inhibir el libre discurrir de narrativas culturales individuales y colectivas que podrían producir los llamados efectos «subversivos» en los que se cuestiona a las colectividades legitimadoras en cuyo nombre se ejerce el poder. Las culturas están constituidas de un modo narrativo a través de descripciones polarizadas de diferenciaciones entre el sí y el otro. El otro no está fuera de la cultu-

42 Para el concepto de «diálogos culturales complejos», ver Benhabib, The Claims of Culture. Equality and Diversity in the Global Era, caps. 1 y 2, y Boaventura de Sousa Santos que observa: «... todas las culturas son incompletas y problemáticas en su concepción de la dignidad humana. La incompletud se deriva del mismo hecho de la existencia de una pluralidad de culturas y esto se percibe mejor desde el exterior, desde la perspectiva de otra cultura. Si cada cultura fuese tan completa como pretende, sólo existiría una única cultura. Elevar la conciencia de la incompletud cultural a su máximo posible es una de las tareas más importantes para la construcción de una concepción multicultural de los derechos humanos». «Toward a Multicultural Conception of Human Rights», en Moral Imperialism. A Critical Anthology, editado por Berta Hernandez-Truyol (New York: New York University Press, 2002), 46-47. 
ra sino que es constitutivo de ella. Las conversaciones interculturales y las intraculturales están profundamente entrelazadas.

Un modo de contemplar los derechos humanos es como condiciones de posibilidad, en los sentidos legal y político, de «iteraciones democráticas no coaccionadas» entre los pueblos y las culturas del mundo. Estas iteraciones no pueden ser concebidas como acuerdos congelados en el espacio y en el tiempo, sino sólo como una conversación continua, como un diálogo complejo que desafía los supuestos de completud de cada cultura al hacer posible a sus miembros el verse a sí mismos desde la perspectiva de los otros. Dado que el objetivo no es un acuerdo irreversible sino la ampliación de perspectivas, la consecuencia de estos diálogos es el educarnos en el grado de variación aceptable en la interpretación y contextualización de los derechos humanos. Se trata de una ampliación de nuestra comprensión de la unidad y diversidad de los derechos humanos a la igualdad y la tolerancia, a la propiedad, la privacidad y la ciudadanía.

Debemos liberar a los derechos humanos de la retórica intervencionista que tan frecuentemente les acompaña. Cuándo, por qué y bajo qué condiciones es justificable la intervención para detener y rectificar las violaciones de los derechos humanos es una cuestión propia de ética política ${ }^{43}$. Entiendo por «ética política» el equilibrio entre intenciones y consecuencias, entre éticas de la responsabilidad y de la convicción (Max Weber). Particularmente cuando los Estados son considerados los únicos agentes con capacidad de intervención y cuando la intervención significa el uso de la fuerza militar, de acuerdo con el derecho internacional, sólo la prevención de genocidios y de limpieza étnica a través de una decisión del Consejo de Seguridad debidamente promulgada puede legitimar estos actos. Estas situaciones entrañan elecciones difíciles que implican el ejercicio del juicio político ${ }^{44}$. Éstas imponen sobre los ciudadanos, líderes y políticos, la «carga de la historia». Creo que la filosofía no puede guiarnos hasta el final de estas deliberaciones ni tampoco garantizarnos que nuestras buenas intenciones no serán destruidas por sucesos contingentes o que

43 El minimalismo sobre los derechos humanos es en el fondo también una preocupación por las políticas intervencionistas que pueden seguirse de una concepción maximalista y pretenciosa de los derechos humanos. Ignatieff es ciertamente explícito sobre este temor. Ver Michael Igantieff, Human Rights as Politics and Idolatry, pp. 90 ss., y también M. Ignatieff, The Lesser Evil (Princeton: Princeton University Press, 2004). Para un análisis de por qué esta línea argumental resulta falaz, y de que no existe una conexión necesario entre la violación de los derechos humanos y las intervenciones humanitarias, excepto en elle caso de genocidios y «crímenes contra la humanidad», como limpiezas étnicas, ver Greg Dinsmore, «When Less is Really Less-What's Wrong with Minimalist Approaches to Human Rights», The Journal of Political Philosophy (2007- Online Primera Versión).

44 Para una formulación incisiva de un intervención «no-legal» pero sin embargo legítima de las tropas de la OTAN en el bombardeo de Belgrado para impedir el genocidio en Kosovo, ver Allen Buchanan, «From Nuremburg to Kosovo: The Morality of Illegal International Legal Reform», Ethics 111 (July 2001): 673-705. 
no se tornarán en su opuesto. Ni debería aspirar a ello. No obstante, como Kant observó ${ }^{45}$, hay una diferencia entre el «moralista político», que abusa de los principios morales para justificar decisiones políticas, y un «político moral», que intenta mantenerse fiel a los principios morales cuando da forma a los acontecimientos políticos. El discurso de los derechos humanos ha sido frecuentemente explotado y abusado por los «moralistas políticos;» su auténtico sitio es guiar al político moral, sean éstos ciudadanos o líderes. Todo cuanto podemos ofrecer como filósofos es una clarificación de lo que podemos considerar como legítimo y justo en el dominio mismo de los derechos humanos.

En esta exposición he argumentado que existe un derecho moral fundamental, el «derecho a tener derechos», de todo ser humano, esto es, el ser reconocido como una persona con derecho a la protección de sus derechos legales. Los derechos humanos articulan principios legales que necesitan que se les dé forma legal. La forma legal de los derechos humanos puede ofrecer variaciones legítimas en interpretaciones y contextualizaciones jurídicas y constitucionales siempre que estas variaciones resulten del ejercicio de la autonomía pública a través de estructuras de autogobierno. Sin autogobierno los derechos humanos se quedan vacíos. Existe una conexión intrínseca, y no meramente contingente, entre los derechos humanos y la autodeterminación democrática. Consecuentemente, he abogado por contemplar los derechos humanos no sólo como condiciones mínimas de legitimidad en la arena internacional — que seguramente también lo son-, sino como condiciones que articulan estándares normativos a los que pueden aspirar los pueblos del mundo. He caracterizado como «iteraciones democráticas» los procesos de interacción entre la formación democrática de la voluntad y de la opinión por una parte, y los principios constitucionales y el derecho internacional por la otra. Los cargos de parroquialismo y eurocentrismo, frecuentemente aireados contra los derechos humanos, sólo pueden ser confrontados cuando las institucionales de autogobierno democrático permiten la expresión y la articulación de diferencias culturales en las esferas públicas libres.

\section{Agradecimientos}

Estoy profundamente agradecida a Kenneth Baynes, Richard Bernstein, Rainer Forst, Thomas A. McCarthy, Robert Post, Amelie Rorty, James Sleeper, Matthew Noah Smith, Tamar Gendler, Shelly Kagan, y a los participantes del Yale Political Theory Colloquium del 7 de diciembre de 2006 por sus comentarios y críticas a borradores anteriores de este texto.

45 Immanuel Kant. [1795]. «Perpetual Peace: A Philosophical Sketch», trad. H.B. Nisbet. En Kant. Political Writings, editado por Hans Reiss (Cambridge: Cambridge Texts in the History of Political Thought, 1994). Segunda edición ampliada. Appendix II, «On the Agreement between Politics and Morality According to the Transcendental Concept of Public Right». 